\title{
Procarbazine, CCNU and vincristine (PCV) versus temozolomide chemotherapy for patients with low-grade glioma: a systematic review
}

\author{
Karim Hafazalla',2, Arjun Sahgal ${ }^{3}$, Blessing Jaja ${ }^{2}$, James R. Perry ${ }^{4}$ and Sunit Das ${ }^{2,5}$ \\ ${ }^{1}$ Sidney Kimmel Medical College at Thomas Jefferson University, Philadelphia, PA, USA \\ ${ }^{2}$ Li Ka Shing Knowledge Institute, St. Michael's Hospital, University of Toronto, Toronto, ON, Canada \\ ${ }^{3}$ Department of Radiation Oncology, Sunnybrook Odette Cancer Centre, University of Toronto, Toronto, ON, Canada \\ ${ }^{4}$ Division of Neurology, Sunnybrook Health Sciences Centre, University of Toronto, Toronto, ON, Canada \\ ${ }^{5}$ Division of Neurosurgery, University of Toronto, Toronto, ON, Canada \\ Correspondence to: Sunit Das, email: sunit.das@utoronto.ca \\ Keywords: glioma; IDH; low-grade glioma; PCV; temozolomide \\ Received: June 15, $2018 \quad$ Accepted: July 16, $2018 \quad$ Published: September 14, 2018 \\ Copyright: Hafazalla et al. This is an open-access article distributed under the terms of the Creative Commons Attribution License \\ 3.0 (CC BY 3.0), which permits unrestricted use, distribution, and reproduction in any medium, provided the original author and \\ source are credited.
}

\section{ABSTRACT}

Low-grade gliomas (LGG) encompass a heterogeneous group of tumors that are clinically, histologically and molecularly diverse. Treatment decisions for patients with LGG are directed toward improving upon the natural history while limiting treatment-associated toxiceffects. Recent evidence has documented a utility for adjuvant chemotherapy with procarbazine, CCNU (lomustine), and vincristine (PCV) or temozolomide (TMZ). We sought to determine the comparative utility of PCV and TMZ for patients with LGG, particularly in context of molecular subtype. A literature search of PubMed was conducted to identify studies reporting patient response to PCV, TMZ, or a combination of chemotherapy and radiation therapy (RT). Eligibility criteria included patients 16 years of age and older, notation of LGG subtype, and report of progression-free survival (PFS), overall survival (OS), and treatment course. Level I, II, and III data were included. Adjuvant therapy with PCV resulted in prolonged PFS and OS in patients with newly diagnosed high-risk LGG. This benefit was accrued most significantly by patients with tumors harboring 1p/19q codeletion and IDH1 mutation. Adjuvant therapy with temozolomide was associated with lower toxicity than therapy with PCV. In patients with LGG with an unfavorable natural history, such as with intact 1p/19q and wild-type IDH1, RT/TMZ plus adjuvant TMZ may be the best option. Patients with biologically favorable high-risk LGG are likely to derive the most benefit from RT and adjuvant PCV.

\section{INTRODUCTION}

Low-grade gliomas (LGG) comprise a small portion of all primary brain tumors, roughly 5 to $10 \%$. These tumors typically arise in younger adults, between 25 and 45 years of age, whereas anaplastic and high-grade tumors are more common in older patients. The natural history of most cases of low-grade gliomas is relatively favorable; examination of untreated patients followed by serial MRI revealed an annual growth rate of 4 to $6 \mathrm{~mm}$ per year [1]. Previous studies had delineated features of increased risk and poorer natural history, including age over 40 years, astrocytic histology, tumor diameter $6 \mathrm{~cm}$ or longer, tumor crossing the midline, and neurological deficit prior to surgery. These features define a group that we will refer to as high-risk LGG [2].

Previous convention differentiated diffuse grade II and III gliomas into two basic subtypes: 
oligodendroglioma and astrocytoma. A third hybrid category, oligoastrocytoma, was used for tumors showcasing both oligodendroglioma and astrocytoma characteristics. Over the last five years, our understanding of LGG has evolved significantly, with a shift from classification of these tumors based on histology towards stratification of risk based on molecular subtype [3, 4]. According to the 2016 WHO classification system, grade II oligodendroglioma is now defined by an isocitrate dehydrogenase (IDH) mutation with whole-arm codeletion of chromosomal arms $1 \mathrm{p}$ and $19 \mathrm{q}$, whereas IDH mutation combined with intact $1 \mathrm{p}$ and $19 \mathrm{q}$ chromosomal status is classified as IDH-mutant astrocytoma. Histological LGG in the setting of wild-type IDH is distinguished from IDHmutant LGG and described as harboring a particularly poor natural history. While histological grade continues to be a factor in treatment consideration, the prognoses of patients with these tumors has been shown to correlate more closely with molecular alterations than with grade $[3,5,6]$.

Treatment of patients with high-risk LGG is directed toward improving on the natural history of the disease, that is, extending time to malignant transformation and overall survival, while limiting treatment-associated morbidities and neurologic disability. Recent evidence has documented a utility for adjuvant chemotherapy with procarbazine, CCNU (lomustine), and vincristine (PCV) or temozolomide (TMZ) in the management of LGG. Unfortunately, most of these studies predate contemporary stratification systems for LGG, and conclusions of published series of glioma need to be re-examined in the light of the shifts that are brought about by the new WHO classification. We sought to determine the comparative utility of PCV and TMZ for patients with LGG, particularly in the context of molecular subtype. This review summarizes published data on adjuvant chemotherapy with PCV or TMZ for patients with LGG.

\section{RESULTS}

Our search of the PubMed database yielded a total of 1,209 papers, of which 19 studies met the inclusion and exclusion criteria: two randomized control trials, thirteen cohort studies, and five retrospective studies (Supplementary Figure 1) [7]. From these studies, 1,720 adult patients were accrued for the systematic review. Table 1 and Table 2 summarize the key findings and survival data for the included studies utilizing PCV and TMZ, respectively. Figure 1, Figure 2, and Figure 3 display superimposed Kaplan-Meier curves from included studies relating OS and PFS to treatment and molecular subtype. Of these 19 papers, ten examined PCV or TMZ as a salvage agent at progression following RT, and were excluded from analysis.

\section{Evidence for use of PCV in patients with LGG}

We identified five studies in which survival outcomes for patients with LGG treated with PCV were reported (Table 1) [8-12]. These studies included 365 patients with a median age of 43.5 years (age range: 36.0 46.5). Of these, four reported survival data meeting our designated requirements for analysis, resulting in a cohort of 344 patients for study with a median age of 43.75 years (age range 36.0-46.5) [8-10, 12]. Taal et al. (2015) reported a median OS of 120 months when using PCV alone [12]. Buckner et al. (2016) reported a median PFS and OS of 48 and 94 months when RT was administered alone, respectively [9]. The median PFS for PCV alone was 32.5 months (PFS range: 19.0-46.0) [10, 12]. PFS when administering PCV in combination with RT was 124.8 median months [9]. Only one study reported 5-year PFS within this context, with $44 \%$ and $61 \%$ PFS for RT and a combination of RT and PCV, respectively [9].

\section{Evidence for use of $\mathrm{PCV}$ in patients with histologically subtyped LGG}

None of the trials identified in our study reported histologic subtype and OS or PFS following treatment with PCV.

\section{Evidence for use of $\mathrm{PCV}$ in patients with molecular-subtyped LGG}

Taal and colleagues reported a median PFS and OS of 35 months and 83 months, respectively, for patients with intact $1 \mathrm{p} / 19 \mathrm{q}$ [12]. Median PFS for patients with 1p/19q codeletion was 67 months; median OS was not reached for patients in this cohort.

Buckner and colleagues treated patients with newly diagnosed high-risk LGG with PCV after radiation therapy at the time of initial diagnosis [9]. IDH1 R132H mutations were detected in 35 of 57 patients $(61 \%)$ in the group that received radiation therapy alone and in 36 of $56(64 \%)$ in the group that received radiation therapy plus chemotherapy. In this cohort, $78 \%$ of patients were diagnosed with oligodendroglioma, 54\% with oligoastrocytoma, and 48\% with astrocytoma. OS was reported as 61.2 and 157.2 median months for patients with wild-type and mutant IDH1, respectively.

\section{Adverse events for patients with LGG treated with PCV}

Completion of therapy was an issue in the study of Taal et al., in which only sixteen patients (50\%) completed six cycles [12]. Toxicities encountered in all studies included bone marrow toxicity, diarrhea, fatigue, and hepatotoxicity. Grade III and IV toxicities were encountered in $47 \%$ and $3 \%$ of patients, respectively. In 
Table 1: Treatment of low-grade glioma using PCV

\begin{tabular}{|c|c|c|c|c|c|c|c|}
\hline Study & $\mathbf{n}$ & $\begin{array}{c}\text { Molecular } \\
\text { Subtype }\end{array}$ & Treatment & $\begin{array}{c}\text { Median OS } \\
\text { (months) }\end{array}$ & $\begin{array}{c}\text { Median PFS } \\
\text { (months) }\end{array}$ & $\begin{array}{c}\text { Median OS } \\
(5 \text {-year \%) }\end{array}$ & $\begin{array}{c}\text { Median PFS } \\
(5 \text {-year \%) }\end{array}$ \\
\hline \multirow[t]{2}{*}{ Buckner et al., 2003 [8] } & 28 & & & & & & \\
\hline & & All & PCV with RT & & & 89.0 & \\
\hline \multirow[t]{5}{*}{ Buckner et al., 2016 [9] } & 251 & & & & & & \\
\hline & & All & RT & 94.0 & 48.0 & 63.0 & 44.0 \\
\hline & & All & PCV with RT & & 124.8 & 72.0 & 61.0 \\
\hline & & IDH1 Wt & PCV with RT & 61.2 & & & \\
\hline & & $I D H 1 \mathrm{Mt}$ & PCV with RT & 157.2 & & & \\
\hline \multirow[t]{2}{*}{ Lebrun et al., 2007 [10] } & 33 & & & & & & \\
\hline & & & $\mathrm{PCV}$ & & 19.0 & 75.0 & \\
\hline \multirow[t]{2}{*}{ Stege et al., 2005 [11] } & 21 & & & & & & \\
\hline & & All & $\mathrm{PCV}$ & & $24.0>$ & & \\
\hline \multirow[t]{4}{*}{ Taal et al., 2015 [12] } & 32 & & & & & & \\
\hline & & All & PCV & 120.0 & 46.0 & & \\
\hline & & $1 p / 19 q$ Intact & $\mathrm{PCV}$ & 83.0 & 35.0 & & \\
\hline & & $1 p / 19 q$ Codeleted & $\mathrm{PCV}$ & NR & 67.0 & & \\
\hline
\end{tabular}

Abbreviations: OS - Overall Survival, PFS - Progression-Free Survival, RT - Radiation Therapy, PCV - procarbazine, CCNU (lomustine), and vincristine, Mt - Mutant, Wt- Wildtype.

the study of Lebrun and colleagues, $9.1 \%$ of 33 patients developed a grade III or IV hematological toxicity [10]. Buckner and colleagues (2003) reported grade III/IV leukopenia and thrombocytopenia in $75 \%$ and $64 \%$ of patients, respectively [8]. Buckner reported grade III and grade IV blood or bone marrow toxicity in $41.6 \%$ and $9.6 \%$ of 125 patients, respectively [8]. In contrast, patients in the radiation-alone treatment group had $0.8 \%$ and $0 \%$ grade III and IV blood or bone marrow toxicity.

\section{Evidence for use of TMZ with LGG}

Fourteen studies assessing survival outcomes with TMZ met our criteria for inclusion (Table 2) [13-26]. These studies included 1,355 patients with a median age of 41 years (age range: 38-49). Of these, six studies reported survival data meeting our designated requirements for analysis, which resulting in a cohort of 933 patients for study with a median age of 41.5 years (age range 38-49) $[13,15,17$, $21,25,26]$. A median OS of 116.4 months was found when administering TMZ on its own [26]. A median 5-year OS of 57.1\% was reported when combining TMZ and RT [15].

An open-label, phase 3 European and Canadian intergroup study randomized adult patients with LGG and at least one high-risk feature to either conformal radiotherapy (up to 50.4 Gy) or dose-dense oral TMZ (for a maximum of 12 cycles). The median PFS for RT alone was 46 months, while median PFS for TMZ alone was 31.0 months (PFS range: 21.8-45.6) [13, 17, 21, 25, $26]$. One study reported median PFS of 54 months when administering TMZ in combination with RT [15]. Five- year PFS was found to be $40.18 \%$ when using RT alone [13]. Median 5-year PFS for TMZ alone was 28.92\% [13].

\section{Evidence for use of TMZ in patients with histologically subtyped LGG}

Only one study reporting on the use of TMZ in patients with LGG included data on histological subtype. Wahl et al reported an OS of 129.6, 85.2, and 68.4 median months for oligodendrogliomas, astrocytomas, and oligoastrocytomas, respectively [26]. The median PFS was 55.2, 39.6, and 32.4 months, for oligodendrogliomas, astrocytomas, and oligoastrocytomas, respectively [26].

\section{Evidence for use of TMZ in patients with molecular-subtyped LGG}

Only one study reporting on the use of TMZ in patients with LGG included data on molecular subtype. A median PFS and OS of 58.8 and 116.4 months were reported for $1 \mathrm{p} / 19 \mathrm{q}$ codeleted patients, respectively [26]. In terms of IDH1, median PFS and OS were 134.4 and 43.2 months for patients with mutant IDH1, respectively, and 21.6 and 7.2 months for patients with wild-type IDH1, respectively [26].

\section{Adverse events for patients with LGG treated with TMZ}

TMZ chemotherapy was also accompanied by adverse effects in all six studies included for analysis. 
Table 2: Treatment of low-grade glioma using TMZ

\begin{tabular}{|c|c|c|c|c|c|c|c|}
\hline Study & $\mathbf{n}$ & $\begin{array}{c}\text { Molecular } \\
\text { Subtype/Histology }\end{array}$ & Treatment & $\begin{array}{l}\text { Median OS } \\
\text { (months) }\end{array}$ & $\begin{array}{c}\text { Median PFS } \\
\text { (months) }\end{array}$ & $\begin{array}{c}\text { Median OS } \\
(5-\text { year \%) }\end{array}$ & $\begin{array}{c}\text { Median PFS } \\
\text { (5-year \%) }\end{array}$ \\
\hline \multirow[t]{3}{*}{ Baumert et al., 2016 [13] } & 477 & & & & & & \\
\hline & & All & RT & & 46.0 & & 40.2 \\
\hline & & All & TMZ & & 39.0 & & 28.9 \\
\hline \multirow[t]{4}{*}{ Dubbink et al., 2009 [14] } & 49 & & & & & & \\
\hline & & All & $\mathrm{TMZ}^{*}$ & 11.0 & & 89.0 & \\
\hline & & $1 p / 19 q$ Intact & $\mathrm{TMZ}^{*}$ & 48.0 & & & \\
\hline & & $1 p / 19 q$ Codeleted & $\mathrm{TMZ}^{*}$ & 98.0 & & & \\
\hline \multirow[t]{2}{*}{ Fisher et al., 2015 [15] } & 129 & & & & & & \\
\hline & & All & TMZ with RT & & 54.0 & 57.1 & \\
\hline \multirow[t]{2}{*}{ Hoang-Xuan et al., 2004 [16] } & 59 & & & & & & \\
\hline & & All & TMZ & & & & \\
\hline \multirow[t]{2}{*}{ Kaloshi et al., 2007 [17] } & 149 & & & & & & \\
\hline & & All & $\mathrm{TMZ}$ & & 28.0 & & \\
\hline \multirow[t]{4}{*}{ Kesari et al., 2009 [18] } & 44 & & & & & & \\
\hline & & All & TMZ & $>72.0$ & 38.0 & 73.0 & 34.0 \\
\hline & & $1 p / 19 q$ Intact & TMZ & & 34.0 & & \\
\hline & & $1 p / 19 q$ Codeleted & TMZ & & 45.0 & & \\
\hline \multirow[t]{2}{*}{ Koekkoek et al., 2016 [19] } & 53 & & & & & & \\
\hline & & All & TMZ & 39.1 & & 20.0 & \\
\hline \multirow[t]{2}{*}{ Kouwenhoven et al., 2006 [20] } & 54 & & & & & & \\
\hline & & All & $\mathrm{TMZ}^{*}$ & 81.0 & & & \\
\hline \multirow[t]{2}{*}{ Levin et al., 2006 [21] } & 28 & & & & & & \\
\hline & & All & TMZ & & 31.0 & & \\
\hline \multirow[t]{2}{*}{ Pace et al., 2003 [22] } & 43 & & & & & & \\
\hline & & All & $\mathrm{TMZ}^{*}$ & & 10.0 & & \\
\hline \multirow[t]{4}{*}{ Quinn et al., 2003 [23] } & 41 & & & & & & \\
\hline & & All & $\mathrm{TMZ}^{*}$ & & 22.0 & & \\
\hline & & OD & $\mathrm{TMZ}^{*}$ & & 22.0 & & \\
\hline & & OA & $\mathrm{TMZ}^{*}$ & & 14.1 & & \\
\hline \multirow[t]{6}{*}{ Taal et al., 2011 [24] } & 58 & & & & & & \\
\hline & & All & $\mathrm{TMZ}^{*}$ & 14.0 & 8.0 & & \\
\hline & & $1 p / 19 q$ Intact & $\mathrm{TMZ}^{*}$ & 12.0 & & & \\
\hline & & $1 p / 19 q$ Codeleted & $\mathrm{TMZ}^{*}$ & 17.0 & & & \\
\hline & & $I D H 1 \mathrm{Wt}$ & $\mathrm{TMZ}^{*}$ & 16.0 & & & \\
\hline & & IDHI Mt & $\mathrm{TMZ}^{*}$ & 12.0 & & NR & 22.0 \\
\hline \multirow[t]{2}{*}{ Tosoni et al., 2008 [25] } & 30 & & & & & & \\
\hline & & All & TMZ & & 21.8 & & \\
\hline \multirow[t]{8}{*}{ Wahl et al., 2017 [26] } & 120 & & & & & & \\
\hline & & All & TMZ & 116.4 & 45.6 & & \\
\hline & & A & TMZ & 85.2 & 39.6 & & \\
\hline & & OD & TMZ & 129.6 & 55.2 & & \\
\hline & & $\mathrm{OA}$ & TMZ & 68.4 & 32.4 & & \\
\hline & & $1 p / 19 q$ Codeleted & TMZ & 116.4 & 58.8 & & \\
\hline & & $I D H 1 \mathrm{Wt}$ & TMZ & 21.6 & 7.2 & & \\
\hline & & $I D H 1 \mathrm{Mt}$ & TMZ & 134.4 & 43.2 & & \\
\hline
\end{tabular}

Abbreviations: OS - Overall Survival, PFS - Progression-Free Survival, A - Astrocytoma, OA - Oligoastrocytoma, OD - Oligodendroglioma, RT - Radiation Therapy, TMZ - Temozolomide, Mt - Mutant, Wt- Wildtype.

${ }^{*} \mathrm{TMZ}$ administered after progression with either prior chemotherapy or radiation therapy. 
Of 234 patients, Baumert and colleagues reported that $34(15 \%)$ had at least one dose reduction, which was due to hematological toxicity in 19 patients $(8 \%)$, nonhematological toxicity in nine patients $(4 \%)$, and for other reasons in $11(5 \%)$ patients. Overall, grade 3-4 haematological toxicity was recorded in $22(9 \%)$ of 235 patients in the safety population who received temozolomide, compared with one $(<1 \%)$ of 228 patients in the safety population in the radiotherapy group. Kaloshi and colleagues reported that patients treated with TMZ chemotherapy tolerated it well, with $7 \%$ grade III and $8 \%$ grade IV myelosuppression. Toxicities encountered in all studies included myelosuppression (including leukopenia, neutropenia and thrombocytopenia) and gastrointestinal complaints (mild nausea, emesis, and constipation).

A

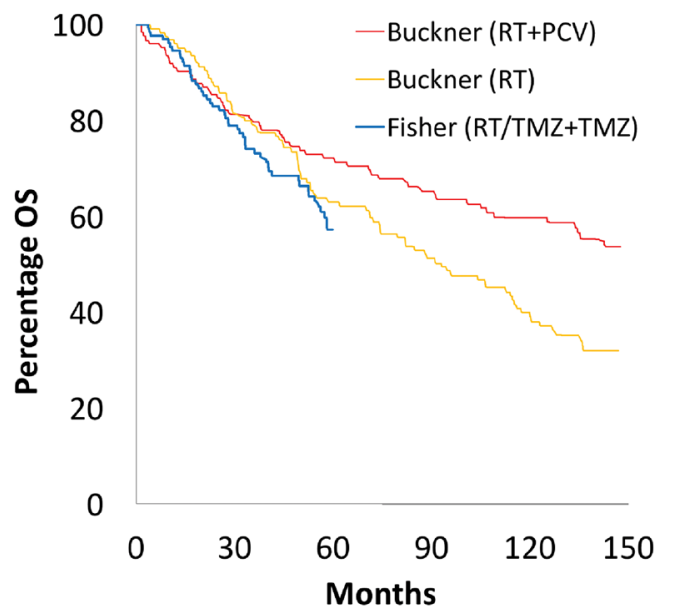

\section{DISCUSSION}

Treatment of patients with LGG is directed toward improving the time to malignant transformation and overall survival, while limiting treatment-associated morbidities and neurologic disability. Objectives for surgery in this patient population include obtaining tissue for diagnosis, improving the quality of life through relief of focal deficits or improved seizure control, and cytoreduction. In a prospective study of patients with LGG with surgeondetermined gross total resection, the presence of residual disease on post-operative imaging, astrocytic histology, and preoperative tumor size were prognostic factors for PFS [13]. In a retrospective population-based parallel cohort study, early surgery afforded a survival benefit compared to biopsy and watchful waiting in patients with low-grade glioma [27].

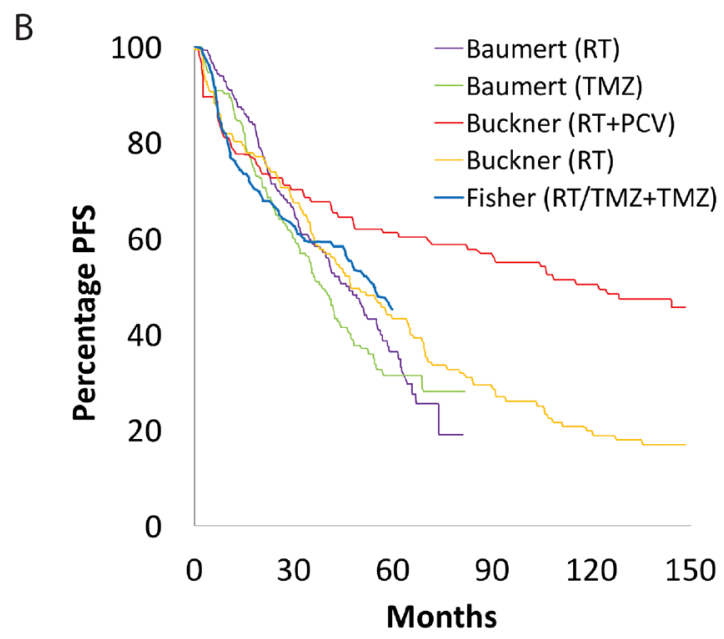

Figure 1: Overall and progression-free survival in patients with low-grade glioma. Kaplan-Meier curve showing superimposed studies that assessed (A) overall and (B) progression-free survival of patients with low-grade glioma.

A

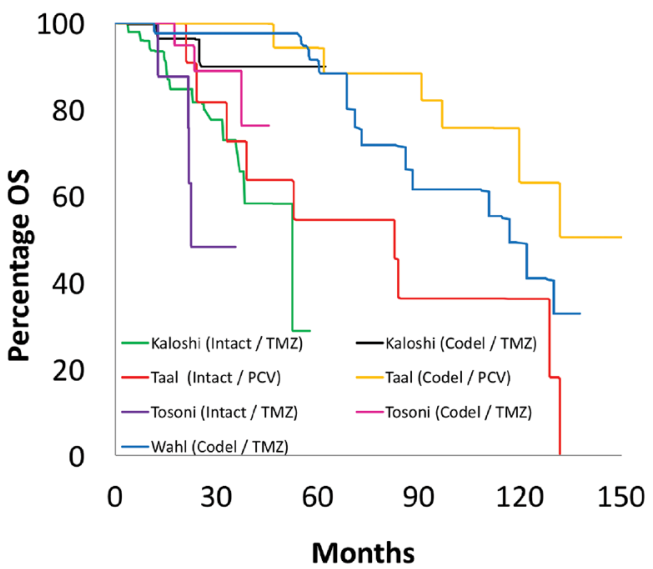

B

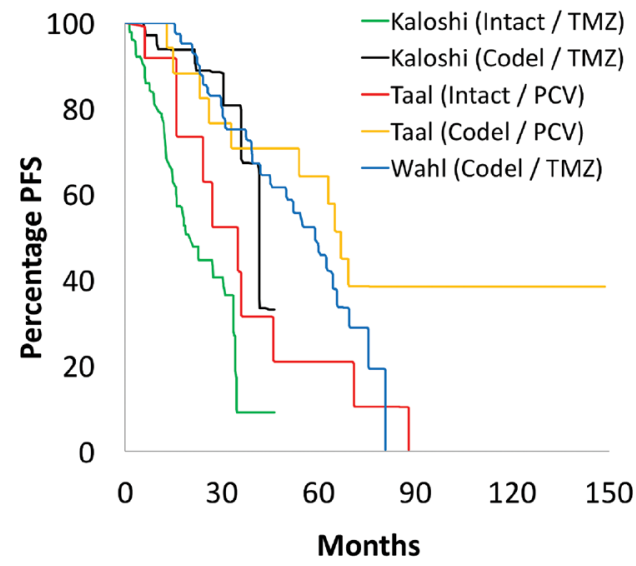

Figure 2: Overall and progression-free survival based on $1 p / 19 q$ status. Kaplan-Meier curve showing superimposed studies that assessed (A) overall and (B) progression-free survival of their patients with low-grade glioma based on $1 p / 19 q$ status. "Intact" and "codel" refer to intact and co-deleted chromosome $1 \mathrm{p}$ and $19 \mathrm{q}$ status. 
The utility of involved field radiation therapy is patients with LGG has been clarified by three independent prospective trials. In an intergroup phase III prospective randomized clinical trial of low- versus high-dose radiation therapy in adults with LGG conducted by the North Central Cancer Treatment Group (NCCTG), Eastern Cooperative Oncology Group (ECOG) and the Radiation Therapy Oncology Group (RTOG), no survival difference was found between patients treated with 54 Gy and 65 Gy, with lower doses tending to be associated with less treatment-related toxicities [28]. Similarly, the EORTC found no difference in survival in patients treated with 45 Gy or 59.4 Gy, again with less adverse treatmentrelated affects in the former group [29]. The EORTC 22845 randomised trial found that early versus delayed RT confered a significant advantage in PFS, but confered no benefit in OS [30]. These findings led many clinicians to reserve radiotherapy for disease progression.

Previous studies from NCIC, the Temodal Brain Tumor Group, and EORTC, have shown a benefit to patients harboring a recurrent anaplastic oligodendroglioma and astrocytoma with both PCV and TMZ [24, 31-34]. The benefit of chemotherapy in this patient group was found to be more frequent and durable responses in patients with histologically classified oligodendroglioma, particularly in those with combined 1p/19q loss, compared with those with an astrocytoma. Four trials investigated adjuvant chemotherapy in addition to radiotherapy. Three of these trials investigated PCV; histologic criteria were used to determine eligibility, with enrollment of patients with anaplastic oligodendroglioma in two of the trials [35, 36], and enrollment of patients with low-grade glioma in the other [9]. The fourth trial investigated concurrent and adjuvant TMZ in patients with

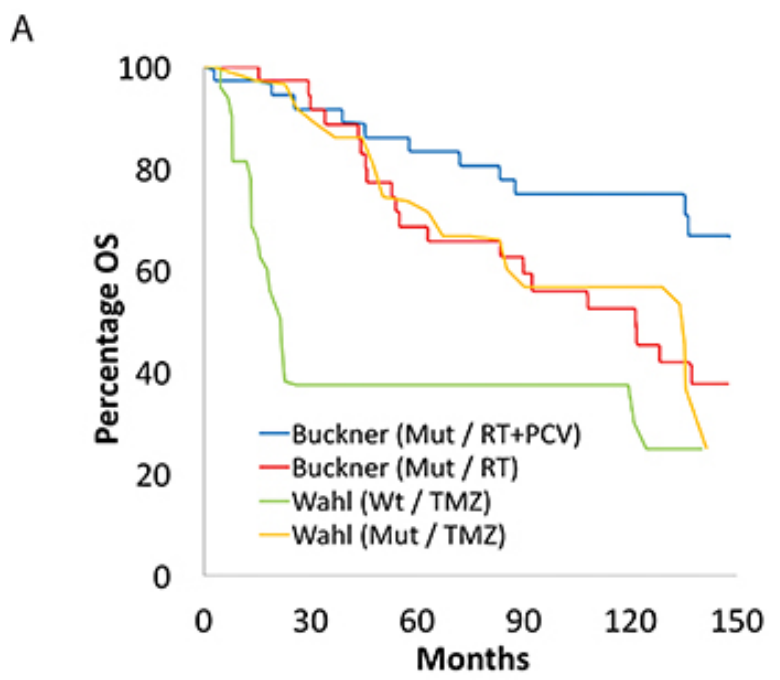

anaplastic glioma with intact chromosomes $1 p$ and $19 q$ $[37,38]$. All four trials found improvements in outcome with the addition of chemotherapy to radiotherapy [9, $35,36,38]$. Both the NCIC and EORTC trials found the addition of PCV chemotherapy to RT in patients with anaplastic $1 p$ and $19 q$ co-deleted tumors to result in improved benefit $[39,40]$. These trials identified three candidate predictive markers for benefit from adjuvant PCV: IDH mutations, $\mathrm{CpG}$ island methylated phenotype, and MGMT promoter methylation [31, 32].

Monotherapy with PCV or TMZ chemotherapy or RT has been investigated by RTOG 0424 (PCV or TMZ versus RT for anaplastic glioma [15]) and EORTC 22033-26033 and NOA-8 (TMZ versus RT in LGG with at least one high-risk feature $[13,41])$. Both trials failed to show improvement in outcome after initial treatment with chemotherapy alone, with the suggestion as well of decreased survival after initial chemotherapy in some patient subgroups). In the absence of the results of a trial that formally compares chemotherapy alone to combined chemotherapy and RT, it is likely most reasonable to conclude that combination therapy improves survival compared with single modality treatment.

Recent molecular studies have shown that IDH wild-type low-grade glioma more closely approximates an early stage of primary glioblastoma than an IDHmutant LGG, and harbours a particularly unfavourable natural history [4]. These findings could be considered as biological support for the recommendation that these patients be treated with adjuvant temozolomide, as has been articulated by the CATNON authors. Conversely, the data predict that patients harbouring an IDH mutant LGG with codeletion of chromosomes $1 p$ and $19 q$ are likely to derive the greatest benefit from adjuvant therapy with

B

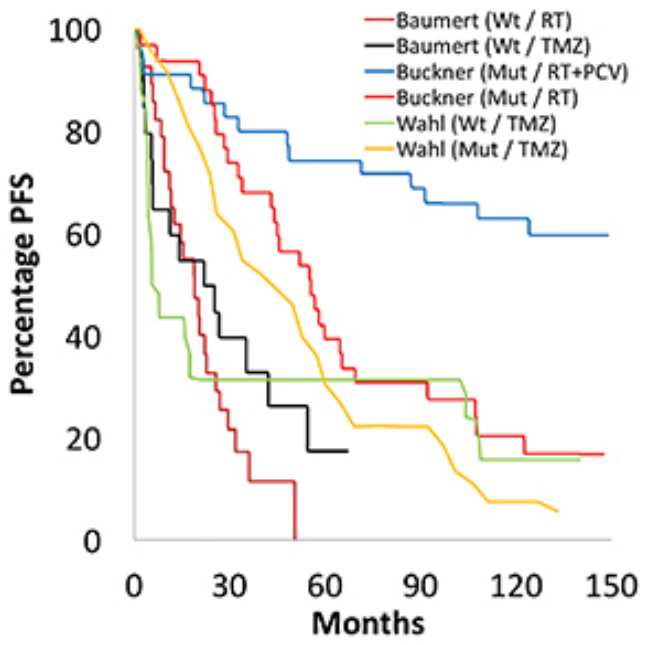

Figure 3: Overall and progression-free survival based on $\boldsymbol{I D H} 1$ status. Kaplan-Meier curve showing superimposed studies that assessed (A) overall and (B) progression-free survival of their patients with low-grade glioma based on IDH1 status. "Wt" and "Mut" refer to wild-type and mutated IDHI. 
PCV. These data offer compelling reason to recommend treatment with radiation followed by adjuvant PCV in patients with an IDH mutant, 1p19q-codeleted tumour. That being said, there is not enough evidence to say RT and $\mathrm{TMZ}$ are an inferior option, as this is primarily due to lack of trials investigating this subject matter.

There is the further concern that TMZ chemotherapy may direct these tumors toward a hypermutator phenotype at the time of progression [42]. It is unclear if the same risk exists with PCV therapy. More critically, these findings were identified through study of a small cohort of patients, and need to be validated in a larger treatment group.

As patients with LGG often experience long periods of disease stability, the effect of therapy on healthrelated quality of life (HRQoL) is all the more critical. While the relatively lesser toxicity of TMZ compared to PCV has led many practitioners to prefer TMZ for their patients with low-grade glioma [43], a recent systematic review of patient-reported HRQoL bemoaned the paucity and heterogeneity of reporting of HRQoL in the LGG literature [44]. A longitudinal study of HRQoL in patients with LGG based on patient self-reporting found that patients with LGG had worse physical role functioning and general health perceptions at long-term follow-up (on average, twelve years following diagnosis) than healthy matched controls, independent of treatment type [45]. No significant differences in HRQoL or global cognitive functioning were seen in patients with high-risk LGG randomized to treatment with TMZ or radiation in EORTC 22033-26033 [46]. While Pace and colleagues performed QoL testing on patients receiving salvage chemotherapy with PCV or TMZ for radiographic progression of LGG, their analysis did not allow for comparison of results from patients in these two subgroups [22]. We were unable to find any other studies in the literature reporting QoL measures on patients with LGG who were treated with PCV.

It is valuable to recollect that the only Level 1 evidence for TMZ in LGG offered by the literature demonstrates the inferiority of TMZ monotherapy to radiation therapy in this patient cohort. Our understanding of the role of TMZ compared to PCV in the treatment of patients with lower-grade glioma will be informed by the CODEL (ALLIANCE-N0577-CODEL) trial, which has reopened as a two-arm comparison of radiation therapy with adjuvant PCV vs. radiation therapy with concurrent and adjuvant TMZ in patients with $1 \mathrm{p} / 19 \mathrm{q}$-codeleted anaplastic (Grade III) oligodendroglioma; whether these findings will be generalizable to patients with Grade II codeleted tumors is unclear. Similarly, in interim results from the CATNON trial (EORTC study 26053-22054), in which patients with newly diagnosed non-co-deleted anaplastic glioma were randomized to RT alone, RT with adjuvant $\mathrm{TMZ}$, or RT with concurrent $\mathrm{TMZ}$ with or without adjuvant TMZ, adjuvant temozolomide chemotherapy was found to be associated with a significant survival benefit compared to RT alone. The data was not yet mature at the time of planned interim analysis to determine superiority between concurrent and adjuvant TMZ versus adjuvant TMZ alone. Unfortunately, IDH status was not reported with the interim analysis for the patient cohort enrolled in CATNON, but will be included in the final analysis. Their findings will likely represent results from a mixed population of IDH wildtype and mutated patient; in fact, the quick separation of the survival curves for patients treated with RT alone versus RT with adjuvant TMZ (within one year of treatment), and the lower than expected number of tumors with MGMT promoter methylation (a finding typical for IDH-mutant LGG), suggest that many of these patients will be found to harbour IDH wild-type tumors.

Our study does not allow us to answer a number of critical real-time problems. For example, how should we advise the patient who has undergone gross total resection of an LGG that harbours histologic, molecular, or demographic features of a high-risk lesion? Some authors have advised that patients who have undergone GTR of an LGG (i.e. no residual FLAIR signal abnormality) may be followed expectantly (a "wait and see approach") and treated if found to have radiographic recurrence [47]. It is unlikely that future trials will include a subgroup that is randomized to treatment with surgical resection alone to allow us the answer to this question. Similarly, the literature reporting on the use of adjuvant therapy in patients with LGG lacks granularity. Should PCV or TMZ be recommended as salvage therapy for a patient who has tumour recurrence following distant radiotherapy for a high-risk LGG without its histological progression? Should PCV or TMZ be used in a patient found to have an intermediate risk lower-grade glioma, for example, a Grade III IDH-mutated, $1 p$ and 19q intact tumour? What patient presentation does a combination of RT and TMZ prove to be the more valuable option of treatment?

Finally, it it is worthwhile to note some of the critical limitations of the data included in our review. For example, these studies all predate the recognition of the intermediate risk LGG represented by tumors harboring an IDH mutation, but lacking $1 p$ and $19 q$ codeletion, and harboring instead deletion of ATRX. In Figure 2, patients captured within the $1 \mathrm{p} 19 \mathrm{q}$-intact cohort may include both this intermediate subgroup and higher-risk patients with IDH wild-type tumors. Conversely, in Figure 3, patients included within the IDH mutant subgroup may include patients with both lower-risk IDH mutant, 1p and 19q codeleted tumours, as well as patients with intermediate IDH mutant, $1 \mathrm{p}$ and 19 intact, ATRX-deleted tumors.

For now, the data suggest that for patients harboring a tumor with an unfavorable natural history, such as those with intact $1 \mathrm{p} / 19 \mathrm{q}$ and wild-type IDH1, TMZ and RT may be the best option. Conversely, the data suggest that patients with biologically favorable LGG are likely to derive the most significant benefit from RT and adjuvant 
PCV. A prospective trial directly comparing PCV and TMZ in patients with high-risk low-grade glioma is needed.

\section{MATERIALS AND METHODS}

This systematic review was conducted according to PRISMA guidelines (Supplementary Figure 2) [7]. The primary literature search was conducted via PubMed for articles published between January 1, 1995 and May 1, 2017, using the search terms, "Low-grade glioma AND temozolomide OR TMZ", "Low-grade glioma AND PCV OR procarbazine/lomustine/vincristine", and "Low-grade glioma AND chemotherapy". References from relevant articles were searched. Level I, II, and III studies were included if published in English, consisted of patients 16 years of age and older, noted LGG subtype, progressionfree survival (PFS) and overall survival (OS) as primary or secondary end points, and treatment course. Exclusion criteria included pediatric patient populations and lack of differentiation of survival data based on treatment or glioma-subtype. Data including study design, patient population demographics, histology, molecular subtype, PFS, OS, and treatment regimens and durations were extracted. Levels of evidence were categorized as follows: level I (properly powered and conducted randomized-control trial), level II (well-designed controlled trial without randomization; prospective comparative cohort trial), and level III (retrospective cohort study) [48]. Figures including superimposed Kaplan-Meier curves were generated using Digitizelt (Bormisoft, Braunschweig, Germany, http://www. digitizeit.de), a software designed to digitize scanned graphs and charts into $(\mathrm{x}, \mathrm{y})$-data. Software errors in data recognition were manually edited by the authors (K.H. and S.D.).

\section{CONCLUSIONS}

In patients harboring a tumor with an unfavorable natural history, such as those with intact $1 \mathrm{p} / 19 \mathrm{q}$ and wildtype IDH1, RT/TMZ plus adjuvant TMZ may be the best option. Conversely, patients with biologically favorable high-risk LGG are likely to derive the most benefit from RT and adjuvant PCV. While unlikely due to the resources and time required, a prospective trial directly comparing PCV and TMZ in patients with high-risk low-grade glioma is needed.

\section{CONFLICTS OF INTEREST}

The authors have declared that no conflict of interest exists. A variation of the abstract within this manuscript was previously presented in poster form at the Society for Neuro-Oncology, San Francisco, CA, USA, November 1619, 2017.

\section{Highlights}

- Low-grade gliomas encompass a clinically and biologically heterogeneous group of tumors.

- Adjuvant therapy with PCV results in prolonged PFS and OS in patients with newly diagnosed high-risk LGG.

- Adjuvant therapy with temozolomide is associated with lower toxicity than therapy with PCV.

- Patients with biologically favorable high-risk LGG are likely to derive the most benefit from RT and adjuvant PCV.

\section{REFERENCES}

1. Rees J, Watt H, Jäger HR, Benton C, Tozer D, Tofts P, Waldman A. Volumes and growth rates of untreated adult low-grade gliomas indicate risk of early malignant transformation. Eur J Radiol. 2009; 72:54-64. https://doi. org/10.1016/j.ejrad.2008.06.013.

2. Pignatti F, van den Bent $M$, Curran D, Debruyne C, Sylvester R, Therasse P, Afra D, Cornu P, Bolla M, Vecht C, Karim AB, and European Organization for Research and Treatment of Cancer Brain Tumor Cooperative Group, and European Organization for Research and Treatment of Cancer Radiotherapy Cooperative Group. Prognostic factors for survival in adult patients with cerebral lowgrade glioma. J Clin Oncol. 2002; 20:2076-84. https://doi. org/10.1200/JCO.2002.08.121.

3. Brat DJ, Verhaak RG, Aldape KD, Yung WK, Salama SR, Cooper LA, Rheinbay E, Miller CR, Vitucci M, Morozova O, Robertson AG, Noushmehr H, Laird PW, et al, and Cancer Genome Atlas Research Network. Comprehensive, Integrative Genomic Analysis of Diffuse Lower-Grade Gliomas. N Engl J Med. 2015; 372:2481-98. https://doi. org/10.1056/NEJMoa1402121.

4. Eckel-Passow JE, Lachance DH, Molinaro AM, Walsh KM, Decker PA, Sicotte H, Pekmezci M, Rice T, Kosel ML, Smirnov IV, Sarkar G, Caron AA, Kollmeyer TM, et al. Glioma Groups Based on 1p/19q, IDH, and TERT Promoter Mutations in Tumors. N Engl J Med. 2015; 372:2499-508. https://doi.org/10.1056/NEJMoa1407279.

5. Dubbink HJ, Atmodimedjo PN, Kros JM, French PJ, Sanson M, Idbaih A, Wesseling P, Enting R, Spliet W, Tijssen C, Dinjens WN, Gorlia T, van den Bent MJ. Molecular classification of anaplastic oligodendroglioma using next-generation sequencing: a report of the prospective randomized EORTC Brain Tumor Group 26951 phase III trial. Neuro Oncol. 2016; 18:388-400. https://doi. org/10.1093/neuonc/nov182.

6. Wiestler B, Capper D, Sill M, Jones DT, Hovestadt V, Sturm D, Koelsche C, Bertoni A, Schweizer L, Korshunov A, Weiß EK, Schliesser MG, Radbruch A, et al. Integrated DNA methylation and copy-number profiling identify three clinically and biologically relevant groups of anaplastic 
glioma. Acta Neuropathol. 2014; 128:561-71. https://doi. org/10.1007/s00401-014-1315-x.

7. Moher D, Liberati A, Tetzlaff J, Altman DG, and PRISMA Group. Preferred reporting items for systematic reviews and meta-analyses: the PRISMA statement. J Clin Epidemiol. 2009; 62:1006-12. https://doi.org/10.1016/j. jclinepi.2009.06.005.

8. Buckner JC, Gesme D Jr, O'Fallon JR, Hammack JE, Stafford S, Brown PD, Hawkins R, Scheithauer BW, Erickson BJ, Levitt R, Shaw EG, Jenkins R. Phase II trial of procarbazine, lomustine, and vincristine as initial therapy for patients with low-grade oligodendroglioma or oligoastrocytoma: efficacy and associations with chromosomal abnormalities. J Clin Oncol. 2003; 21:25155. https://doi.org/10.1200/JCO.2003.06.023.

9. Buckner JC, Shaw EG, Pugh SL, Chakravarti A, Gilbert MR, Barger GR, Coons S, Ricci P, Bullard D, Brown PD, Stelzer K, Brachman D, Suh JH, et al. Radiation plus Procarbazine, CCNU, and Vincristine in Low-Grade Glioma. N Engl J Med. 2016; 374:1344-55. https://doi. org/10.1056/NEJMoa1500925.

10. Lebrun C, Fontaine D, Bourg V, Ramaioli A, Chanalet $\mathrm{S}$, Vandenbos F, Lonjon $\mathrm{M}$, Fauchon $\mathrm{F}$, Paquis $\mathrm{P}$, Frenay M. Treatment of newly diagnosed symptomatic pure low-grade oligodendrogliomas with PCV chemotherapy. Eur J Neurol. 2007; 14:391-98. https://doi. org/10.1111/j.1468-1331.2007.01675.x.

11. Stege EM, Kros JM, de Bruin HG, Enting RH, van Heuvel I, Looijenga LH, van der Rijt CD, Smitt PA, van den Bent MJ. Successful treatment of low-grade oligodendroglial tumors with a chemotherapy regimen of procarbazine, lomustine, and vincristine. Cancer. 2005; 103:802-09. https://doi. org/10.1002/cncr.20828.

12. Taal W, van der Rijt CC, Dinjens WN, Sillevis Smitt PA, Wertenbroek AA, Bromberg JE, van Heuvel I, Kros JM, van den Bent MJ. Treatment of large low-grade oligodendroglial tumors with upfront procarbazine, lomustine, and vincristine chemotherapy with long follow-up: a retrospective cohort study with growth kinetics. J Neurooncol. 2015; 121:36572. https://doi.org/10.1007/s11060-014-1641-9.

13. Baumert BG, Hegi ME, van den Bent MJ, von Deimling A, Gorlia T, Hoang-Xuan K, Brandes AA, Kantor G, Taphoorn MJ, Hassel MB, Hartmann C, Ryan G, Capper $\mathrm{D}$, et al. Temozolomide chemotherapy versus radiotherapy in high-risk low-grade glioma (EORTC 22033-26033): a randomised, open-label, phase 3 intergroup study. Lancet Oncol. 2016; 17:1521-32. https://doi.org/10.1016/ S1470-2045(16)30313-8.

14. Dubbink HJ, Taal W, van Marion R, Kros JM, van Heuvel I, Bromberg JE, Zonnenberg BA, Zonnenberg CB, Postma TJ, Gijtenbeek JM, Boogerd W, Groenendijk FH, Smitt $\mathrm{PA}$, et al. IDH1 mutations in low-grade astrocytomas predict survival but not response to temozolomide. Neurology. 2009; 73:1792-95. https://doi.org/10.1212/ WNL.0b013e3181c34ace.
15. Fisher BJ, Hu C, Macdonald DR, Lesser GJ, Coons SW, Brachman DG, Ryu S, Werner-Wasik M, Bahary JP, Liu J, Chakravarti A, Mehta M. Phase 2 study of temozolomidebased chemoradiation therapy for high-risk low-grade gliomas: preliminary results of Radiation Therapy Oncology Group 0424. Int J Radiat Oncol Biol Phys. 2015; 91:497504. https://doi.org/10.1016/j.ijrobp.2014.11.012.

16. Hoang-Xuan K, Capelle L, Kujas M, Taillibert S, Duffau H, Lejeune J, Polivka M, Crinière E, Marie Y, Mokhtari K, Carpentier AF, Laigle F, Simon JM, et al. Temozolomide as initial treatment for adults with low-grade oligodendrogliomas or oligoastrocytomas and correlation with chromosome 1p deletions. J Clin Oncol. 2004; 22:3133-38. https://doi.org/10.1200/JCO.2004.10.169.

17. Kaloshi G, Benouaich-Amiel A, Diakite F, Taillibert S, Lejeune J, Laigle-Donadey F, Renard MA, Iraqi W, Idbaih A, Paris S, Capelle L, Duffau H, Cornu P, et al. Temozolomide for low-grade gliomas: predictive impact of $1 \mathrm{p} / 19 \mathrm{q}$ loss on response and outcome. Neurology. 2007; 68:1831-36. https://doi.org/10.1212/01. wnl.0000262034.26310.a2.

18. Kesari S, Schiff D, Drappatz J, LaFrankie D, Doherty L, Macklin EA, Muzikansky A, Santagata S, Ligon KL, Norden AD, Ciampa A, Bradshaw J, Levy B, et al. Phase II study of protracted daily temozolomide for low-grade gliomas in adults. Clin Cancer Res. 2009; 15:330-37. https://doi.org/10.1158/1078-0432.CCR-08-0888.

19. Koekkoek JA, Dirven L, Heimans JJ, Postma TJ, Vos MJ, Reijneveld JC, Taphoorn MJ. Seizure reduction is a prognostic marker in low-grade glioma patients treated with temozolomide. J Neurooncol. 2016; 126:347-54. https:// doi.org/10.1007/s11060-015-1975-y.

20. Kouwenhoven MC, Kros JM, French PJ, Biemond-ter Stege EM, Graveland WJ, Taphoorn MJ, Brandes AA, van den Bent MJ. 1p/19q loss within oligodendroglioma is predictive for response to first line temozolomide but not to salvage treatment. Eur J Cancer. 2006; 42:2499-503. https://doi.org/10.1016/j.ejca.2006.05.021.

21. Levin N, Lavon I, Zelikovitsh B, Fuchs D, Bokstein F, Fellig Y, Siegal T. Progressive low-grade oligodendrogliomas: response to temozolomide and correlation between genetic profile and O6-methylguanine DNA methyltransferase protein expression. Cancer. 2006; 106:1759-65. https://doi. org/10.1002/cncr.21809.

22. Pace A, Vidiri A, Galiè E, Carosi M, Telera S, Cianciulli AM, Canalini P, Giannarelli D, Jandolo B, Carapella CM. Temozolomide chemotherapy for progressive low-grade glioma: clinical benefits and radiological response. Ann Oncol. 2003; 14:1722-26. https://doi.org/10.1093/annonc/ mdg502.

23. Quinn JA, Reardon DA, Friedman AH, Rich JN, Sampson JH, Provenzale JM, McLendon RE, Gururangan S, Bigner DD, Herndon JE 2nd, Avgeropoulos N, Finlay J, Tourt-Uhlig S, et al. Phase II trial of temozolomide in patients with progressive 
low-grade glioma. J Clin Oncol. 2003; 21:646-51. https://doi. org/10.1200/JCO.2003.01.009.

24. Taal W, Dubbink HJ, Zonnenberg CB, Zonnenberg BA, Postma TJ, Gijtenbeek JM, Boogerd W, Groenendijk FH, Kros JM, Kouwenhoven MC, van Marion R, van Heuvel I, van der Holt B, et al, and Dutch Society for Neuro-Oncology. First-line temozolomide chemotherapy in progressive low-grade astrocytomas after radiotherapy: molecular characteristics in relation to response. Neuro Oncol. 2011; 13:235-41. https://doi.org/10.1093/neuonc/noq177.

25. Tosoni A, Franceschi E, Ermani M, Bertorelle R, Bonaldi L, Blatt V, Brandes AA. Temozolomide three weeks on and one week off as first line therapy for patients with recurrent or progressive low grade gliomas. J Neurooncol. 2008; 89:179-85. https://doi.org/10.1007/s11060-008-9600-y.

26. Wahl M, Phillips JJ, Molinaro AM, Lin Y, Perry A, HaasKogan DA, Costello JF, Dayal M, Butowski N, Clarke JL, Prados M, Nelson S, Berger MS, Chang SM. Chemotherapy for adult low-grade gliomas: clinical outcomes by molecular subtype in a phase II study of adjuvant temozolomide. Neuro Oncol. 2017; 19:242-51. https://doi.org/10.1093/ neuonc/now176.

27. Jakola AS, Myrmel KS, Kloster R, Torp SH, Lindal S, Unsgård G, Solheim O. Comparison of a strategy favoring early surgical resection vs a strategy favoring watchful waiting in low-grade gliomas. JAMA. 2012; 308:1881-88. https://doi.org/10.1001/jama.2012.12807.

28. Shaw E, Arusell R, Scheithauer B, O'Fallon J, O'Neill B, Dinapoli R, Nelson D, Earle J, Jones C, Cascino T, Nichols D, Ivnik R, Hellman R, et al. Prospective randomized trial of low- versus high-dose radiation therapy in adults with supratentorial low-grade glioma: initial report of a North Central Cancer Treatment Group/Radiation Therapy Oncology Group/Eastern Cooperative Oncology Group study. J Clin Oncol. 2002; 20:2267-76. https://doi. org/10.1200/JCO.2002.09.126.

29. Karim AB, Maat B, Hatlevoll R, Menten J, Rutten EH, Thomas DG, Mascarenhas F, Horiot JC, Parvinen LM, van Reijn M, Jager JJ, Fabrini MG, van Alphen AM, et al. A randomized trial on dose-response in radiation therapy of low-grade cerebral glioma: European Organization for Research and Treatment of Cancer (EORTC) Study 22844. Int J Radiat Oncol Biol Phys. 1996; 36:549-56. https://doi. org/10.1016/S0360-3016(96)00352-5.

30. van den Bent MJ, Afra D, de Witte O, Ben Hassel M, Schraub S, Hoang-Xuan K, Malmström PO, Collette L, Piérart M, Mirimanoff R, Karim AB, and EORTC Radiotherapy and Brain Tumor Groups and the UK Medical Research Council. Long-term efficacy of early versus delayed radiotherapy for low-grade astrocytoma and oligodendroglioma in adults: the EORTC 22845 randomised trial. Lancet. 2005; 366:985-90. https://doi.org/10.1016/ S0140-6736(05)67070-5.

31. Cairncross G, Macdonald D, Ludwin S, Lee D, Cascino T, Buckner J, Fulton D, Dropcho E, Stewart D, Schold
C Jr. Chemotherapy for anaplastic oligodendroglioma. National Cancer Institute of Canada Clinical Trials Group. J Clin Oncol. 1994; 12:2013-21. https://doi.org/10.1200/ JCO.1994.12.10.2013.

32. Cairncross JG, Ueki K, Zlatescu MC, Lisle DK, Finkelstein DM, Hammond RR, Silver JS, Stark PC, Macdonald DR, Ino Y, Ramsay DA, Louis DN. Specific genetic predictors of chemotherapeutic response and survival in patients with anaplastic oligodendrogliomas. J Natl Cancer Inst. 1998; 90:1473-79. https://doi.org/10.1093/jnci/90.19.1473.

33. Yung WK, Prados MD, Yaya-Tur R, Rosenfeld SS, Brada M, Friedman HS, Albright R, Olson J, Chang SM, O’Neill AM, Friedman AH, Bruner J, Yue N, et al, and Temodal Brain Tumor Group. Multicenter phase II trial of temozolomide in patients with anaplastic astrocytoma or anaplastic oligoastrocytoma at first relapse. J Clin Oncol. 1999; 17:2762-71. https://doi.org/10.1200/ JCO.1999.17.9.2762.

34. van den Bent MJ, Taphoorn MJ, Brandes AA, Menten J, Stupp R, Frenay M, Chinot O, Kros JM, van der Rijt CC, Vecht CJ, Allgeier A, Gorlia T, and European Organization for Research and Treatment of Cancer Brain Tumor Group. Phase II study of first-line chemotherapy with temozolomide in recurrent oligodendroglial tumors: the European Organization for Research and Treatment of Cancer Brain Tumor Group Study 26971. J Clin Oncol. 2003; 21:2525-28. https://doi.org/10.1200/ JCO.2003.12.015.

35. Cairncross G, Wang M, Shaw E, Jenkins R, Brachman D, Buckner J, Fink K, Souhami L, Laperriere N, Curran W, Mehta M. Phase III trial of chemoradiotherapy for anaplastic oligodendroglioma: long-term results of RTOG 9402. J Clin Oncol. 2013; 31:337-43. https://doi. org/10.1200/JCO.2012.43.2674.

36. van den Bent MJ, Brandes AA, Taphoorn MJ, Kros JM, Kouwenhoven MC, Delattre JY, Bernsen HJ, Frenay M, Tijssen CC, Grisold W, Sipos L, Enting RH, French PJ, et al. Adjuvant procarbazine, lomustine, and vincristine chemotherapy in newly diagnosed anaplastic oligodendroglioma: long-term follow-up of EORTC brain tumor group study 26951. J Clin Oncol. 2013; 31:344-50. https://doi.org/10.1200/JCO.2012.43.2229.

37. Hildebrand J, Gorlia T, Kros JM, Afra D, Frenay M, Omuro A, Stupp R, Lacombe D, Allgeier A, van den Bent MJ, and EORTC Brain Tumour Group investigators. Adjuvant dibromodulcitol and BCNU chemotherapy in anaplastic astrocytoma: results of a randomised European Organisation for Research and Treatment of Cancer phase III study (EORTC study 26882). Eur J Cancer. 2008; 44:1210-16. https://doi.org/10.1016/j.ejca.2007.12.005.

38. van den Bent MJ, Baumert B, Erridge SC, Vogelbaum MA, Nowak AK, Sanson M, Brandes AA, Clement PM, Baurain JF, Mason WP, Wheeler H, Chinot OL, Gill S, et al. Interim results from the CATNON trial (EORTC study 26053-22054) of treatment with concurrent and adjuvant 
temozolomide for $1 \mathrm{p} / 19 \mathrm{q}$ non-co-deleted anaplastic glioma: a phase 3, randomised, open-label intergroup study. Lancet. 2017; 390:1645-53. https://doi.org/10.1016/ S0140-6736(17)31442-3.

39. Cairncross JG, Wang M, Jenkins RB, Shaw EG, Giannini C, Brachman DG, Buckner JC, Fink KL, Souhami L, Laperriere NJ, Huse JT, Mehta MP, Curran WJ Jr. Benefit from procarbazine, lomustine, and vincristine in oligodendroglial tumors is associated with mutation of IDH. J Clin Oncol. 2014; 32:783-90. https://doi.org/10.1200/ JCO.2013.49.3726.

40. van den Bent MJ, Erdem-Eraslan L, Idbaih A, de Rooi J, Eilers PH, Spliet WG, den Dunnen WF, Tijssen C, Wesseling P, Sillevis Smitt PA, Kros JM, Gorlia T, French PJ. MGMT-STP27 methylation status as predictive marker for response to $\mathrm{PCV}$ in anaplastic Oligodendrogliomas and Oligoastrocytomas. A report from EORTC study 26951. Clin Cancer Res. 2013; 19:5513-22. https://doi. org/10.1158/1078-0432.CCR-13-1157.

41. Wick W, Roth P, Hartmann C, Hau P, Nakamura M, Stockhammer F, Sabel MC, Wick A, Koeppen S, Ketter R, Vajkoczy P, Eyupoglu I, Kalff R, et al, and Neurooncology Working Group (NOA) of the German Cancer Society. Long-term analysis of the NOA-04 randomized phase III trial of sequential radiochemotherapy of anaplastic glioma with PCV or temozolomide. Neuro Oncol. 2016; 18:152937. https://doi.org/10.1093/neuonc/now133.

42. Johnson BE, Mazor T, Hong C, Barnes M, Aihara K, McLean CY, Fouse SD, Yamamoto S, Ueda H, Tatsuno K, Asthana S, Jalbert LE, Nelson SJ, et al. Mutational analysis reveals the origin and therapy-driven evolution of recurrent glioma. Science. 2014; 343:189-93. https://doi.org/10.1126/ science. 1239947.
43. Liu R, Solheim K, Polley MY, Lamborn KR, Page M, Fedoroff A, Rabbitt J, Butowski N, Prados M, Chang SM. Quality of life in low-grade glioma patients receiving temozolomide. Neuro Oncol. 2009; 11:59-68. https://doi. org/10.1215/15228517-2008-063.

44. Fountain DM, Allen D, Joannides AJ, Nandi D, Santarius T, Chari A. Reporting of patient-reported health-related quality of life in adults with diffuse low-grade glioma: a systematic review. Neuro Oncol. 2016; 18:1475-86. https:// doi.org/10.1093/neuonc/now107.

45. Boele FW, Douw L, Reijneveld JC, Robben R, Taphoorn MJ, Aaronson NK, Heimans JJ, Klein M. Health-related quality of life in stable, long-term survivors of low-grade glioma. J Clin Oncol. 2015; 33:1023-29. https://doi. org/10.1200/JCO.2014.56.9079.

46. Reijneveld JC, Taphoorn MJ, Coens C, Bromberg JE, Mason WP, Hoang-Xuan K, Ryan G, Hassel MB, Enting RH, Brandes AA, Wick A, Chinot O, Reni M, et al. Healthrelated quality of life in patients with high-risk low-grade glioma (EORTC 22033-26033): a randomised, open-label, phase 3 intergroup study. Lancet Oncol. 2016; 17:1533-42. https://doi.org/10.1016/S1470-2045(16)30305-9.

47. Shaw EG, Berkey B, Coons SW, Bullard D, Brachman D, Buckner JC, Stelzer KJ, Barger GR, Brown PD, Gilbert MR, Mehta M. Recurrence following neurosurgeondetermined gross-total resection of adult supratentorial low-grade glioma: results of a prospective clinical trial. J Neurosurg. 2008; 109:835-41. https://doi.org/10.3171/ JNS/2008/109/11/0835.

48. DeVries JG, Berlet GC. Understanding levels of evidence for scientific communication. Foot Ankle Spec. 2010; 3:205-09. https://doi.org/10.1177/1938640010375184. 